\title{
COORDINATING UNIONS, WAGES AND EMPLOYMENT
}

\section{INTRODUCTION}

Wage setting arrangements differ fundamentally in Western economies. They vary from decentralized wage setting, mainly at the level of the firm, to centralized bargaining between national union movements and employer federations. Examples of the former are the US and Japan, and of the latter the Scandinavian countries and Austria. Countries where bargaining takes place at industry level can be found too, for instance The Netherlands and Belgium. In some of these countries, individual unions have become affiliated into a federation of unions. Centralized wage setting arrangements allow macroeconomic considerations to be taken into account. Recently, several authors have discussed the consequences of different wage setting arrangements on the levels of wages and employment and on macroeconomic performance (see, e.g. Nickell and Andrews (1983), Gylfason and Lindbeck (1984a) and (1984b), Abraham (1987), Calmfors and Driffill (1988) and Mulder (1988) and (1989)).

Following ideas of Oswald (1979) and (1982), we consider a two-sector economy with two unions, one in each sector. We assume that unions care about the real wage (of their members) and the level of employment in their sector of industry. The unions are mutually dependent upon each other: wage claims of one union influence the utility of the other union. The central question we study in this paper is whether coordination between unions leads to lower wages and higher employment, compared to the situation where unions do not cooperate. This question is particularly relevant for countries like The Netherlands, in which federations of unions exist that are, in principle, able to coordinate member unions' strategies. A classical remedy against too high an unemployment rate is a reduction in the real wage level. In a multi-sector

* University of Groningen, Department of Economics, P.O. Box 800, 9700 AV Groningen, The Netherlands. Preliminary versions of this paper were presented at seminars at the University of Oldenburg and the University of Groningen and the Fourth Annual Congress of the European Economic Association, Augsburg, September 2-4, 1989. The authors would like to thank W.H. Buiter, H. van Ees, J. Hartog, Th. v.d. Klundert, S.K. Kuipers, Chr. Mulder and T. van Veen for their comments on an earlier version of this paper. 
economy a sectorial wage reduction has to be distinguished from an economywide wage reduction. A reduction in sectorial wages accompanied by the same demand as before will be associated with an increase in employment. When wages are reduced throughout the economy, the outcome, however, is not obvious. If the demand diminishes as a result of the wage decrease, the positive effect might be off-set by a shortage of demand. In that case a decrease in the overall wage level may lead to higher unemployment. Since Keynes's General Theory, this phenomenon has been known as the fallacy of composition. Our model captures both cases.

In the mainstream literature on trade unions, there are two approaches to the modelling of the outcome of the bargaining process between a union and a firm. Firstly, in the monopoly model the union tries to maximize its utility function given the demand for labour. In this case the union sets the wage and the firm the level of employment, given this wage rate. Secondly, the efficient bargains model has the union maximizing its utility function subject to some minimum level of profit for the firm. In that case the parties are bargaining about their respective positions on a contract curve. Nickell and Andrews' (1983) 'right to manage' model offers an alternative. They suppose that, although unions are aware of the demand curve, they and the employers actually bargain about the wage. We opt for the monopoly model in this paper, which is a special case of the right-to-manage model, to keep the analysis as simple as possible. The union sets the wage and the firms adjust their demand for labour correspondingly.

In our two-sector economy a wage claim of a union in one sector has not only a direct effect on the employment level in its own sector, but also an indirect effect on employment in the other sector. We have to distinguish positive and negative externalities, which correspond to spill-over and envy effects as introduced by Gylfason and Lindbeck (1984b). A positive (negative) externality indicates that agents in one sector benefit from an increase (decrease) in the wage set by the union in the other sector. If positive (negative) externalities exist, non-cooperating unions set their wage claims too low (high). If the unions coordinate their activities, the result will be a higher wage in case of a positive externality and a lower wage in case of a negative externality. Attention is focused upon the concept of strategic complementarity as well. Applied to the game played between the unions in our model, this is the feature that the optimal wage level of a union depends positively on the wage set by the other union, see e.g. Cooper and John (1988).

We need a model of the whole economy to derive the indirect effect of a wage claim of a union in one sector and on employment in the other sector. The heart of our model has been derived from Cooper (1988) and is similar to e.g. Hart (1982). Cooper builds a two-sector general equilibrium model with imperfect competition. He assumes that firms choose output levels and that prices equate demand and supply in each sector. Crucial to his and our model is the circular flow of money. Our model differs from Cooper's model in the determination 
of wages: Cooper assumes wages to be exogenous, while in our model wages are set by unions. The general equilibrium model considered has interesting features, apart from the issue of coordination between unions. Firstly, the model may exhibit multiplier effects. A necessary and sufficient condition for multiplier effects is strategic complementarity, the concept discussed earlier. Secondly, the multiplier increases if the number of firms in a sector becomes larger.

A game is defined that consists of two subgames. In the first subgame unions play against each other and determine the equilibrium wage vector. In the second subgame first determine the demand for labour given the outcome of the first subgame, the wage, and the demand for goods. The solution of the game is tackled the other way around. Firstly, the sectorial output is derived for each sector as a function of the output in the other sector, for a given wage level. Then the subgame played between the unions is solved. The outcome of this (first) subgame is the wage vector. The unions know the effects of their wage claims on the demand for labour by firms, they know how the outcome of the second subgame is influenced by their wage claims. The consequences of coordination can easily be ascertained. The outcomes in terms of wages and employment for non-cooperative unions are compared with the outcomes when unions coordinate.

Our model is closely related to Abraham (1987). In his model externalities arise as well, but he comes to a different conclusion. There are two important differences in assumptions between Abraham's model and our model. Firstly, whereas Abraham assumes competitive domestic goods markets, we assume the goods markets to be oligopolistic. Secondly, our model has explicit microfoundations. Abraham's main conclusion is that in his model a wage increase in one industry reduces the real wage rate and employment levels in other industries and thus creates a negative externality. Our model, on the other hand, may result in negative as well as positive externalities.

The paper is organized as follows. First the second game is described. The demand for labour by firms has to be derived for all combinations of wage levels. For this purpose a model of the whole economy is required. The model is presented in section 2 . In section 3 the second game is solved and the impact of wages on employment is derived. Moreover, multiplier effects are discussed. Union behaviour is not introduced until section 4 . The first game, the one between the unions, is solved in this section. The final section contains some concluding remarks.

\section{THE MODEL}

Before the effects of union behaviour on the wage level and employment can be determined, a model of the whole economy is needed. We consider a small open economy consisting of two sectors $(A$ and $B$ ) in which six types of agents are operating: for each sector one type of firm, one type of household and one 
union. There are four domestic markets: two goods markets and two labour markets (one for each sector). Households' labour is assumed to be sector specific: there is no labour mobility between sectors. For simplicity we assume that households and (owners of) firms do not consume goods produced in their own sector. There is a foreign economy which demands goods from both sectors and produces a good that is demanded by all types of domestic inhabitants. The foreign good serves as numeraire and its price is set equal to 1 . A sector consists of $n$ firms which are assumed to be Cournot oligopolists in their homogeneous goods market. Prices equate demand and supply on the goods markets. The outline of our model starts by discussing the behaviour of firms and households. They treat wages as given. The wage is the outcome of the game played between wage setting unions. This (second) game is not considered until section 4.

The following notation is used throughout the paper. The subscript ' $i j$ ' denotes firm $j$ in sector $i(i=A, B) ; p_{i}$ and $w_{i}$ are the output price, respectively the wage rate for sector $i, y_{i j}$ is the output of firm $j$ in sector $i, L_{i j}$ is the level of employment and $\pi_{i j}$ is the profit of that firm. $y_{i}\left(=\sum_{j=1}^{n} y_{i j}\right)$ is sector $i$ 's output which is equal to total demand for the goods produced by sector $i{ }^{1}$ All firms are assumed to have the same linear technology in which labour is the only type of input. We choose our units such that the constant marginal productivity of labour is equal to one:

$$
y_{i j}=L_{i j}-\sigma \quad i=A, B, \quad j=1, \ldots, n
$$

where $\sigma>0$ is a parameter which can be interpreted as a fixed labour input. The incorporation of $\sigma$ in the production function has the implication that the technology exhibits increasing returns to scale. The profit $\pi_{i j}$ firm $j$ in sector $i$ receives is equal to

$$
\pi_{i j}=p_{i} y_{i j}-w_{i} L_{i j}=\left(p_{i}-w_{i}\right) y_{i j}-w_{i} \sigma \text {. }
$$

Firms choose a profit maximizing output level $y_{i j}$. The owners of firms spend their profits on the goods produced in the other sector $y_{-i}$ and on foreign goods $y_{f}$. This structure of production and consumption is an idealized representation of the fact that individuals specialize in production and generalize in consumption. The structure facilitates the computations and does not influence the qualitative results. The utility of a firm (or more precisely their owners) is of the form

$$
U_{i j}^{F}=\left[\left(y_{-i}^{F}\right)_{i j}\right]^{\alpha}\left[\left(y_{f}^{F}\right)_{i j}\right]^{1-\alpha} \quad i=A, B, \quad j=1, \ldots, n \quad \text { and } 0<\alpha<1
$$

1 In order not to complicate the notation too much we do not make a distinction in notation between quantities demanded and quantities supplied. 
and their budget constraint is

$$
p_{-i}\left(y_{-i}^{F}\right)_{i j}+\left(y_{f}^{F}\right)=\pi_{i j}
$$

where $\left(y_{-i}^{F}\right)_{i j}$ denotes firm $i j$ 's demand for the goods produced in the other sector and $\left(y_{f}^{F}\right)_{i j}$ denotes firm $i j$ 's demand for the foreign goods.

Similarly, households derive utility from consumption of the goods produced in the other sector and of foreign goods. The utility function for household sector $i$ as a whole is of the form

$$
U_{i}^{H}=\left[\left(y_{-i}^{H}\right)_{i}\right]^{\beta}\left[\left(y_{f}^{H}\right)_{i}\right]^{1-\beta} \quad i=A, B, \quad 0<\beta<1(\beta \neq \alpha),
$$

where $\left(y_{-i}^{H}\right)_{i}$ denotes total demand of households in sector $i$ for goods produced in the other sector; $\left(y_{f}^{H}\right)_{i}$ stands for total demand of households in sector $i$ for the foreign goods. Households maximize this utility function subject to the budget constraint

$$
p_{-i}\left(y_{-i}^{H}\right)_{i}+\left(y_{f}^{H}\right)_{i}=w_{i} L_{i}
$$

where $w_{i} L_{i}$ is labour income; $L_{i}$ is determined by firms's demand for labour. As noted above, we assume labour to be sector specific. Special skills and knowledge are required in each sector so households can only find a job within their own sector.

A leakage in the circular flow of money is created by the introduction of a foreign economy. The foreign economy (or the rest of the world) consumes the foreign goods and both domestic goods. Its income $I_{f}$ is assumed to be exogenous to the model (which is a version of the small country assumption). The decision problem of the foreign economy can be written as the maximization problem

$$
\begin{aligned}
& \max U^{f}=\left(y_{A}^{f}\right)^{\gamma}\left(y_{B}^{f}\right)^{\gamma}\left(y_{f}^{f}\right)^{1-2 \gamma} \quad 0<\gamma<\frac{1}{2} \\
& \text { subject to } p_{A} y_{A}^{f}+p_{B} y_{B}^{f}+y_{f}^{f}=I_{f},
\end{aligned}
$$

where $y_{A}^{f}$ denotes foreign demand for $\operatorname{good} A, y_{B}^{f}$ foreign demand for $\operatorname{good} B$ and $y_{f}^{f}$ foreign demand for the foreign goods.

All three utility maximizing problems can be solved in the same way by setting the marginal rate of substitution between two goods equal to the price ratio (see Varian (1984, p. 116-117)). Making use of the budget constraints, the demand for goods $y_{A}$ and $y_{B}$ by households, firms and the foreign economy can 
be derived. The demand from all these different sources can be aggregated to the sectorial demands:

$$
\begin{aligned}
y_{A}= & \frac{\alpha \pi_{B}}{p_{A}}+\frac{\beta w_{B}\left(y_{B}+n \sigma\right)}{p_{A}}+\frac{\gamma I_{f}}{p_{A}}= \\
& \frac{\alpha p_{B} y_{B}+(\beta-\alpha) w_{B}\left(y_{B}+n \sigma\right)+\gamma I_{f}}{p_{A}} \\
y_{B}= & \frac{\alpha \pi_{A}}{p_{B}}+\frac{\beta w_{A}\left(y_{A}+n \sigma\right)}{p_{B}}+\frac{\gamma I_{f}}{p_{B}}= \\
& \frac{\alpha p_{A} y_{A}+(\beta-\alpha) w_{A}\left(y_{A}+n \sigma\right)+\gamma I_{f}}{p_{B}}
\end{aligned}
$$

Walras' law assures that the balance of payments is in equilibrium. This can be seen as follows. Adding equations (1) and (2) gives

$$
p_{A} y_{A}+p_{B} y_{B}=\alpha\left(\pi_{A}+\pi_{B}\right)+\beta\left(w_{A} L_{A}+w_{B} L_{B}\right)+2 \gamma I_{f} .
$$

Using the fact that $p_{i} y_{i}=\pi_{i}+w_{i} L_{i}, i=A, B$ gives

$$
(1-\alpha)\left(\pi_{A}+\pi_{B}\right)+(1-\beta)\left(w_{A} L_{A}+w_{B} L_{B}\right)=2 \gamma I_{f},
$$

which is the equilibrium condition for the balance of payments.

Thus, demand in sector $i$ depends, among other things, on the production in the other sector $-i$. Firms take sectorial demand curves for goods and the wage to be paid as given. Therefore, the profit maximizing output level $y_{i j}^{*}$ depends on the output levels chosen by the other firms in the same sector $y_{i, j}$ $\left(=\sum_{k \neq j} y_{i k}\right)$ and on the total output level of the other sector, i.e. a firm's reaction curve is of the form,

$$
y_{i j}^{*}=f\left(y_{i,-j}, y_{-i} ; w_{A}, w_{B}\right)
$$

In the next section we will give expressions for these 'reaction curves.'

For every pair of wages $\left(w_{A}, w_{B}\right)$ we define a Nash equilibrium in output as a vector of output levels $\left(y_{A 1}^{*}, \ldots, y_{A n}^{*}, y_{B 1}^{*}, \ldots, y_{B n}^{*}\right)$ such that

$$
y_{i j}^{*}=f\left(y_{i,-j}^{*}, y_{-i}^{*} ; w_{A}, w_{B}\right) \quad i=A, B \text { and } j=1, \ldots, n .
$$

To every equilibrium output level corresponds an equilibrium demand for labour $L_{i j}^{*}\left(w_{A}, w_{B}\right)$. In the following section we will discuss the impact of wages on employment. 


\section{THE IMPACT OF WAGES ON EMPLOYMENT}

In the previous section we have defined a Nash equilibrium in output for given $w_{A}$ and $w_{B}$. To determine the Nash equilibrium we start by looking at the profit maximizing condition for firm $j$ in sector $i$ :

$$
\left(p_{i}-w_{i}\right)+y_{i j}\left(\partial p_{i} / \partial y_{i j}\right)=0 \quad i=A, B .
$$

The demand curves (1) and (2) can be inverted to get

$$
p_{i}=\frac{R_{i}}{y_{i j}+y_{i,-j}}, \quad i=A, B
$$

where $R_{i}=\alpha p_{-i} y_{-i}+(\beta-\alpha) w_{-i}\left(y_{-i}+n \sigma\right)+\gamma I_{f}, i=A, B . R_{i}$ can be interpreted as the total amount of numeraire spent on good $y_{i}$ by the other sector and the foreign economy. Equation (3) can now be rewritten as

$$
\frac{R_{i}}{y_{i j}+y_{i,-j}}-w_{i}-y_{i j} \frac{R_{i}}{\left(y_{i j}+y_{i,-j}\right)}=0 .
$$

To determine a symmetric Nash equilibrium within sector $i$ we have to solve (5) using the symmetry condition $(n-1) y_{i j}=y_{i,-j}$. The output level in sector $i$ is then given by

$$
y_{i}=\frac{\xi R_{i}}{w_{i}},
$$

where $0<\xi \equiv(n-1) / n<1$ is a measure of competitiveness. Note that if $\xi=0$, there is only one firm, a monopolist, in a sector. In the following, we exclude the monopoly case because the profit maximizing output level is indeterminate in the monopoly case. A non-negative profit condition implies an upper bound on the number of firms per sector, $n .^{2}$

Equations (6) and (4) imply that $p_{i}=w_{i} / \xi$ so that prices are simply a markup over wages. Substituting the last equality into the demand curves (1) and (2) yields a useful relation between the level of activity in both sectors:

$$
\begin{aligned}
& y_{A}=\frac{w_{B}}{w_{A}}[\alpha+(\beta-\alpha) \xi] y_{B}+\frac{w_{B}(\beta-\alpha) \xi n \sigma+\gamma \xi I_{f}}{w_{A}} \\
& y_{B}=\frac{w_{A}}{w_{B}}[\alpha+(\beta-\alpha) \xi] y_{A}+\frac{w_{A}(\beta-\alpha) \xi n \sigma+\gamma \xi I_{f}}{w_{B}}
\end{aligned}
$$

2 The upper limit is the largest integer that satisfies the condition $\pi_{i j}=(1 / \xi-1) w_{i} y_{i j}-w_{i} \sigma \geq 0$ and can be calculated by means of equation (9) or (10) below. 
We will refer to these relations as 'reaction curves.' Note that these are not proper reaction curves, because they already incorporate the requirements for a Nash equilibrium within a sector. Still, equations (6) and (7) indicate the reaction of a whole sector, in equilibrium, to an output level of the other section. The notion of a reaction curve is thus used in a loose way. In Figure 1 equations (6) and (7) are drawn for given $w_{A}, w_{B}$ and $I_{f}$. The 'reaction curves' are upward sloping, because $\alpha+(\beta-\alpha) \xi>0$. The figure shows that the output levels of the different sectors are strategic complements of each other: an increase in output in sector $i$ leads to a rise in demand in the other sector.

The intersection point of the two reaction curves in the figure is the Nash equilibrium in output for a given pair of wages as defined in the previous section. The equilibrium can be computed by substituting (7) into (6) and is given by

$$
\begin{aligned}
& y_{A}^{*}=\frac{(\beta-\alpha) \xi n \sigma+\gamma \xi I_{f} / w_{A}}{1-[\alpha+(\beta-\alpha) \xi]}+\frac{(\beta-\alpha) \xi n \sigma\left[w_{B} / w_{A}-1\right]}{1-[\alpha+(\beta-\alpha) \xi]^{2}} \\
& y_{B}^{*}=\frac{(\beta-\alpha) \xi n \sigma+\gamma \xi I_{f} / w_{B}}{1-[\alpha+(\beta-\alpha) \xi]}+\frac{(\beta-\alpha) \xi n \sigma\left[w_{A} / w_{B}-1\right]}{1-[\alpha+(\beta-\alpha) \xi]^{2}}
\end{aligned}
$$

The intuition behind this result may be grasped as follows. Consider a change in $I_{f}$. This change causes the reaction curves (7) and (8) to shift outwards. This is illustrated in Figure 2.

The immediate or first order impact of a change $\Delta I_{f}$ on the reaction curves (7) and (8) is $\gamma \xi / w_{A}$ times $\Delta I_{f}, \gamma \xi / w_{B}$ times $\Delta I_{f}$ for respectively $y_{A}$ and $y_{B}$. However, since $y_{A}$ is influenced by $y_{B}$ and vice versa, there are higher order

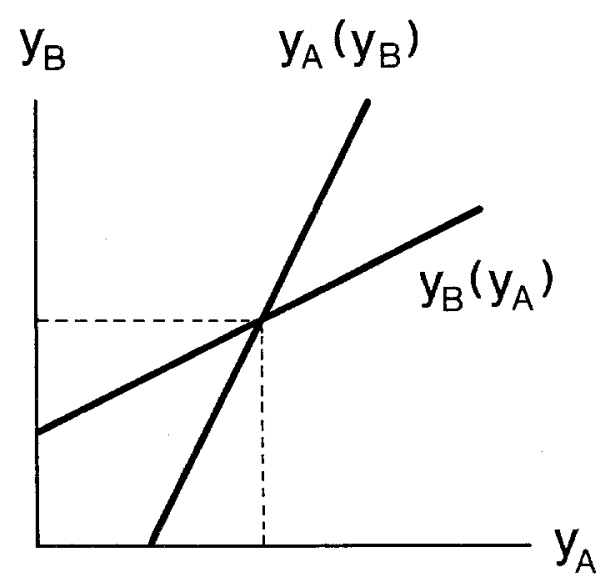

Figure 1 


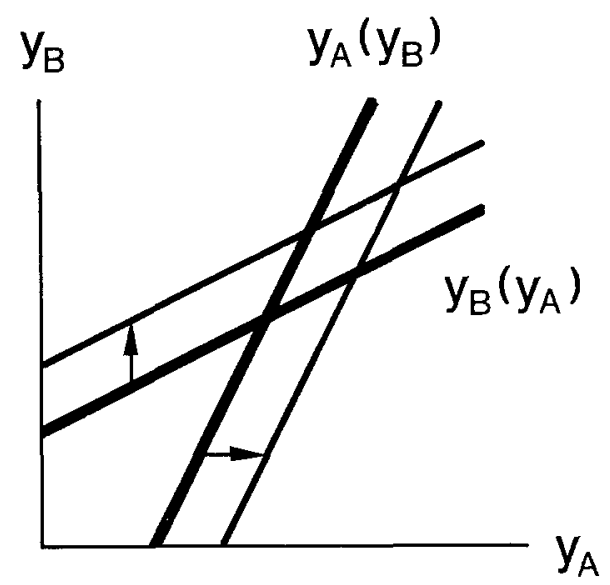

Figure 2

impacts too. The total effect of $\Delta I_{f}$ on $y_{A}$, for example, is

$$
\begin{aligned}
\Delta y_{A} & =\left\{\gamma \xi / w_{A}+[\alpha+(\beta-\alpha) \xi] \gamma \xi / w_{A}+[\alpha+(\beta-\alpha) \xi]^{2} \gamma \xi / w_{A}+\cdots\right\} \Delta I_{f} \\
& =\frac{\gamma \xi}{1-[\alpha+(\beta-\alpha) \xi]} \frac{\Delta I_{f}}{w_{A}} \equiv m \frac{\Delta I_{f}}{w_{A}} .
\end{aligned}
$$

The equality holds because $0<[\alpha+(\beta-\alpha) \xi]<1$ for all values $0<\alpha, \beta, \xi<1$. The multiplier $m$ is precisely the coefficient with which $I_{f}$ enters equation (9). The multiplier effect is a consequence of the strategic complementarity between the two sectors. The equation above shows that small shocks from abroad may induce large changes in the home economy. Similar expressions can be obtained for the impact of $w_{A}$ and $w_{B}$ on $y_{A}$ and of $I_{f}, w_{A}$ and $w_{B}$ on $y_{B}$.

A striking feature is that $\partial m / \partial \xi>0$, which means that the multiplier becomes larger as sectors become more competitive. This result can be explained from equations (3) and (6). Equation (3) shows that the profit maximizing output level depends among others on $\partial p_{i} / \partial y_{i j}$. This term becomes less negative when the number of firms increases. The other terms in equation (3) are not affected by the number of firms, $n$. To put it differently, as the number of firms increases, the negative impact of an increase in the output of a single firm on the sectorial price level decreases. Optimizing output levels thus increase as the sector becomes more competitive. This results in equation (6) from which it can be seen that a Nash equilibrium within a sector is increasing in the degree of competitiveness. This is a familiar result in the partial equilibrium theory of market forms. It is the main source behind the result that the multiplier is increasing in the number of firms in case there is strategic complementarity.

In the analysis of union behaviour, the impact of a change in $w_{A}\left(\right.$ or $\left.w_{B}\right)$ on 
the equilibrium levels of sectorial output (employment) turns out to be a crucial quantity. Therefore, we will look at $\partial y_{i}^{*} / \partial w_{i}$ and $\partial y_{-i}^{*} / \partial w_{i}$. Equations (9) and (10) reveal that $\partial y_{-i}^{*} / \partial w_{i}$ is positive (negative) as $\beta>\alpha(\beta<\alpha)$.

The explanation runs along the following lines. The demand for good $Y_{-i}$ by sector $i$ consists of a fraction $\beta$ of labour income, $w_{i} L_{i}$ and a fraction $\alpha$ of profit, $\pi_{i}$. Labour income equals

$$
w_{i} L_{i}=w_{i} y_{i}+w_{i} n \sigma=\xi R_{i}+w_{i} n \sigma
$$

from equation (6). Profits can be rewritten as

$$
\pi_{i}=\left(p_{i}-w_{i}\right) y_{i}-w_{i} n \sigma=\left(\xi^{-1}-1\right) w_{i} y_{i}-w_{i} n \sigma=(1-\xi) R_{i}-w_{i} n \sigma .
$$

Since $R_{i}$ is given for sector $i$, labour income is increasing in $w_{i}$, while profits are decreasing in $w_{i}$. How is the demand for good $y_{-i}$ affected by a change in $w_{i}$ ? If households in sector $i$ consume more goods of the other sector than owners of firms do $(\beta>\alpha)$, then demand for sector $-i$ increases as wages go up. The reverse holds true if $\beta<\alpha$. If $\alpha$ is equal to $\beta$ the demand for sector $-i$ goods is not affected by a change in $w_{i}$.

The evaluation of $\partial y_{i}^{*} / \partial w_{i}$ is slightly more complicated. In appendix $\mathrm{A}$ it is shown that $\partial y_{i}^{*} / \partial w_{i}, i=A, B$ cannot be positive. A summary of the possible configurations is given in Table 1 and is illustrated in Figure 3 when the impact of an upward shift in $w_{B}$ is depicted.

The regions I and II in Figure 3 correspond to the distinguished cases in Table 1. We have shown that an upward shift in $w_{B}$ will never lead to a Nash equilibrium in regions III and IV. In the figure, case II is depicted. In the analysis of union behaviour the difference between regions I and II turns out to be rather crucial.

For the outcomes of our model only the difference in consumption behaviour of households and firms is crucial. The assumption regarding increasing returns to scale, the incorporation of $\sigma>0$ in the production function, is only crucial in the sense that in case of decreasing returns to scale $(\sigma<0)$, the conditions with respect to $\alpha$ and $\beta$ have to be reversed. Only in the case $\sigma=0$ differences in consumption behaviour of households and firms are not important. The assumption on the type of the utility functions used is not crucial either. Cobb-Douglas functions have the advantage of making the computations more tractable. Differences in the behaviour of firms and households are crucial in our model.

TABLE 1

\begin{tabular}{lll}
\hline Case & Parameter Values & Result \\
\hline I & $\alpha>\beta$ & $\partial y_{i}^{*} / \partial w_{i}<0, \partial y_{-i}^{*} / \partial w_{i}<0$ \\
\hline II & $\alpha<\beta$ & $\partial y_{i}^{*} / \partial w_{i}<0, \partial y_{-i}^{*} / \partial w_{i}>0$ \\
\hline
\end{tabular}




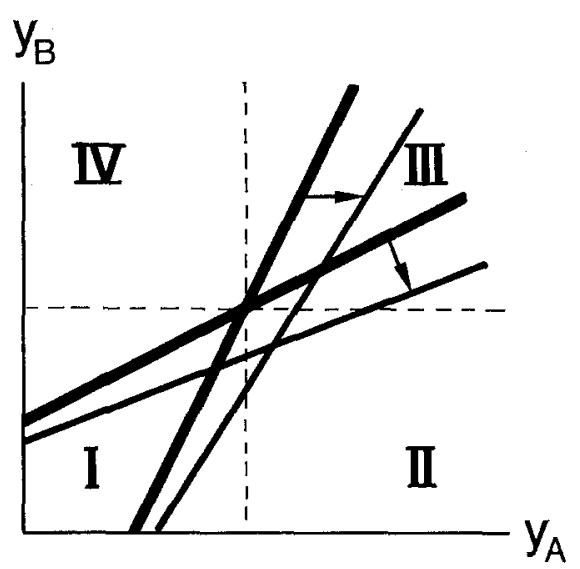

Figure 3

4 UNION BEHAVIOUR

Now it is time to consider union behaviour. Unions are assumed to set the wage level in their own sector in such a way as to maximize a quasi-concave CobbDouglas utility function with (real) wages and sectorial employment as arguments:

$$
U_{i}=\left(w_{i} / P^{i}\right)^{\theta}\left(L_{i}^{*}\right)^{1-\theta} \quad i=A, B, \theta \neq \frac{1}{2},^{3}
$$

where $P^{i}=\left(p_{-i}\right)^{\beta} \times(1)^{1-\beta}=\left(w_{-i} / \xi\right)^{\beta}$ is a consumption price index appropriate to households in sector $i{ }^{4}$ Note that unions know that firms choose their Nash strategies. Labour supply is assumed sufficient to cover $L_{i}^{*}$. Since $L_{i}^{*}$ depends not only on $w_{i}$ but also on $w_{-i}$, the utility maximizing wage level for union $i$ $\left(w_{i}^{*}\right)$ depends on the wage level set by the other union. A union's reaction curve has the form

$$
w_{i}^{*}=g\left(w_{-i}\right) \quad i=A, B .
$$

We define a Nash equilibrium in wages as a wage pair $\left(w_{A}^{*}, w_{B}^{*}\right)$ such that

$$
w_{i}^{*}=g\left(w_{-i}^{*}\right) \quad i=A, B
$$

Firstly, we consider the situation that the two unions do not coordinate their activities. In case I of the previous section higher wages in sector $i$ lead to lower

3 If $\theta=\frac{1}{2}$ utility is the square root of a linear function of wages. Such a utility function does not have a maximum value for any wage level.

4 When membership of the union is discerned as a separate argument in the utility function of the union, the results do not change fundamentally. 
output in sector $-i$ and hence to lower employment. Higher wages in a sector also imply that prices in the same sector increase so that the consumption price index in the other sector becomes larger. As unions set the wage level in their own sector, this indicates that case I exhibits a negative externality. The opposite may be true for case II. In case II higher wages in sector $i$ imply higher employment levels in the other sector. Case II exhibits a positive externality provided that this positive effect is not offset by the corresponding increase in the consumption price index (see below).

A positive externality is related to the fallacy of composition argument. A reduction in wages in sector $i$ may seem to be necessary to achieve higher employment in the same sector. However, if lower wages imply lower employment in the other sector, which is true for case II, then an economy-wide reduction in wages may offset the direct employment effect in the own sector through a reduction in demand.

If the union does not incorporate the (positive or negative) externality into its own decision, the first order condition for utility maximization is ${ }^{5}$ :

$$
\theta \frac{L_{i}^{*}}{w_{i}}+(1-\theta) \frac{\partial L_{i}^{*}}{\partial w_{i}}=0 \quad i=A, B
$$

Since $L_{i}^{*}$ is directly related to $y_{i}^{*}$, it depends on $w_{-i}$. The optimal choice $w_{i}^{*}$ thus depends also on $w_{-i}$. The 'reaction curves' $w_{i}\left(w_{-i}\right)$ are given by

$$
\begin{aligned}
w_{i}= & \frac{1-2 \theta}{\theta}\left[\frac{1+\alpha+(\beta-\alpha) \xi}{1-\alpha[\alpha+(\beta-\alpha) \xi]}\right] \frac{\gamma \xi I_{f}}{n \sigma} \\
& +\frac{1-2 \theta}{\theta}\left[\frac{(\beta-\alpha) \xi}{1-\alpha[\alpha+(\beta-\alpha) \xi]}\right] w_{-i} \quad i=A, B .
\end{aligned}
$$

and the Nash equilibrium in wages is given by

$$
w_{A}^{*}=w_{B}^{*}=(1-2 \theta)\left\{\frac{1+\alpha+(\beta-\alpha) \xi}{\theta\left(1-\alpha^{2}\right)+(2 \theta-1-\alpha \theta)(\beta-\alpha) \xi}\right\} \frac{\gamma \xi I_{f}}{n \sigma}
$$

Equations (11) and (12) are derived in appendix B.

In order to get meaningful results $w_{A}^{*}$ and $w_{B}^{*}$ have to be positive. This means that we have one of the following cases:

$$
0<\theta<\frac{1}{2} \text { and } \beta<\alpha+\frac{\theta\left(1-\alpha^{2}\right)}{\xi(1+\alpha \theta-2 \theta)} .
$$

5 It is easy to see that $P^{i}$, the consumption price index, does not depend on $w_{i}$ since $P^{i}=\left(p_{-i}\right)^{\beta}$ and $p_{-i}=w_{-i} / \xi$. 
Two different situations may arise:

a) $\beta<\alpha$. In this case we have a negative externality. See Case I of Table 1.

b) $\alpha<\beta<\alpha+\frac{\theta\left(1-\alpha^{2}\right)}{\xi(1+\alpha \theta-2 \theta)}$.

In this case a positive externality is possible; see Case II of Table 1 and the discussion below.

(ii) $\quad 1 /(2-\alpha)<\theta<1$ and $\beta<\alpha+\frac{\theta\left(1-\alpha^{2}\right)}{\xi(1+\alpha \theta-2 \theta)}<\alpha$.

In this case we again have a negative externality, see Case I of Table 1.

At first sight, we have a third case in which $\frac{1}{2}<\theta<1 /(2-\alpha)$ and $\beta>$ $\alpha+\theta\left(1-\alpha^{2}\right)[\xi(1+\alpha \theta-2 \theta)]^{-1}$. From equation (10) we see that in this case both reaction curves have negative intercepts and negative slopes. Hence, there is no intersection of the curves in the first quadrant. This situation can be ruled out because $\beta>\alpha+\theta\left(1-\alpha^{2}\right)(\xi(1+\alpha \theta-2 \theta))^{-1}$ is equivalent to $\beta>1$.

Next, consider the possibility of coordination between unions. If unions coordinate their activities, $w_{A}$ and $w_{B}$ are set such that

$$
\lambda\left\{\left(w_{A} / P^{A}\right)^{\theta}\left(L_{A}^{*}\right)^{1-\theta}\right\}+(1-\lambda)\left\{\left(w_{B} / P^{B}\right)^{\theta}\left(L_{B}^{*}\right)^{1-\theta}\right\}, \quad 0<\lambda<1
$$

is maximized; $\lambda$ reflects the relative bargaining power of the two unions. This implies that the following first order conditions must hold:

$$
\begin{gathered}
\frac{\lambda \theta}{p^{A}}\left(\frac{L_{A}^{*}}{w_{A} / p^{A}}\right)^{1-\theta}+\lambda(1-\theta)\left(\frac{L_{A}^{*}}{w_{A} / p^{A}}\right)^{-\theta} \frac{\partial L_{A}^{*}}{\partial w_{A}} \\
+(1-\lambda)(1-\theta)\left(\frac{L_{B}^{*}}{w_{B} / p^{B}}\right)^{-\theta} \frac{\partial L_{B}^{*}}{\partial w_{A}} \\
-\frac{(1-\lambda) \theta \beta}{\xi}\left(\frac{w_{A}}{\xi}\right)^{\beta-1} \frac{w_{B}}{p^{B^{2}}}\left(\frac{L_{B}^{*}}{w_{B} / p^{B}}\right)^{1-\theta}=0
\end{gathered}
$$

and

$$
\begin{gathered}
\lambda(1-\theta)\left(\frac{L_{A}^{*}}{w_{A} / p^{A}}\right)^{-\theta} \frac{\partial L_{A}^{*}}{\partial w_{B}}-\frac{\lambda \theta \beta}{\xi}\left(\frac{w_{B}}{\xi}\right)^{\beta-1} \frac{w_{A}}{p^{A^{2}}}\left(\frac{L_{A}^{*}}{w_{A} / p^{A}}\right)^{1-\theta} \\
+\frac{(1-\lambda) \theta}{p^{B}}\left(\frac{L_{B}^{*}}{w_{B} p^{B}}\right)^{1-\theta}+(1-\lambda)(1-\theta)\left(\frac{L_{B}^{*}}{w_{B} / p^{B}}\right)^{-\theta} \frac{\partial L_{B}^{*}}{\partial w_{B}}=0 .
\end{gathered}
$$


In general, it is not possible to give expressions for the wage levels in the two sectors if unions coordinate their activities. Some qualitative statements, however, can be made.

Cases (i)a and (ii), distinguished above, are the easiest to discuss. In these cases, unions incorporate the negative impact of their wage level on the employment level in the other sector. Higher wages in one sector also imply a higher consumption price index in the other sector. Both effects point in the same direction. Therefore we have negative externality in these cases: the cooperative wage level is below the Nash equilibrium level. Case (ii) is depicted in Figure 4b.

Coordination of activities leads to higher wages if there is a positive externality. We have seen that a positive externality may exist in Case II of Table 1. The difficulty in this case is that a high wage level in one sector has two opposite

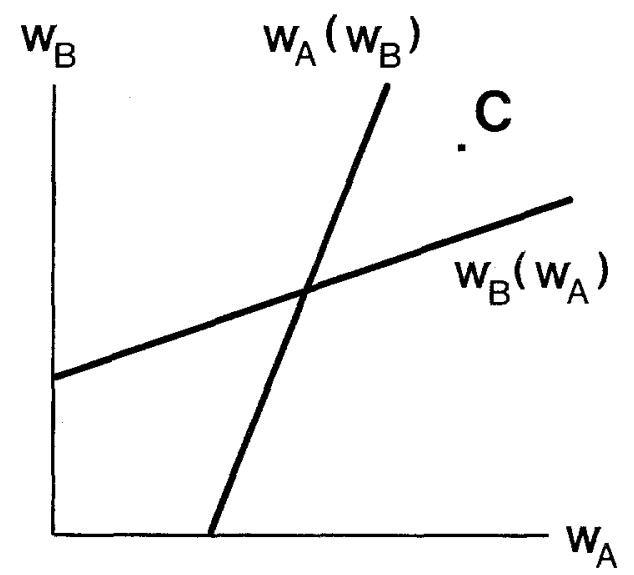

Figure 4a

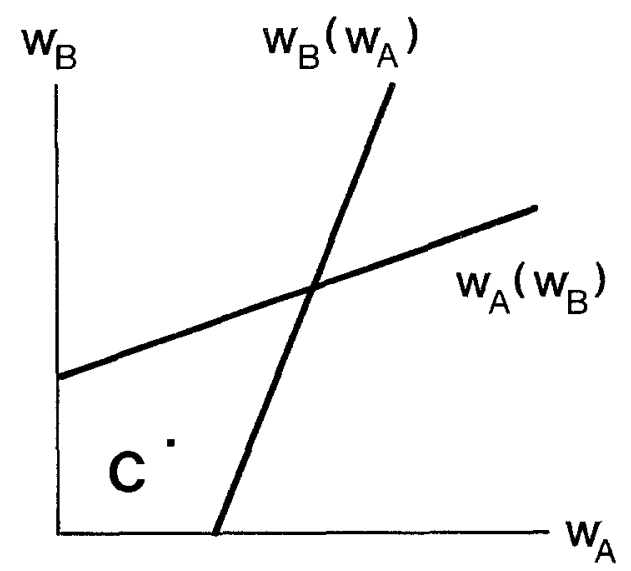

Figure $4 \mathrm{~b}$ 
effects: a positive impact on the employment level in the other sector and a positive impact on the consumption price index. If the former impact outweighs the latter, a positive externality results. A positive externality exists if the last two terms of equation (13) and the first two terms of equation (14) are positive. This is the case if, and only if,

$$
(1-\theta) \frac{\partial L_{B}^{*}}{\partial w_{B}}>\theta \beta \frac{\partial L_{B}^{*}}{\partial w_{B}}
$$

If $\theta$ is close enough to zero the inequality holds and we arrive at point $C$ in Figure $4 \mathrm{a}$. Thus, a positive externality cannot be excluded on theoretical grounds. One union can raise employment in its own sector by setting the wage level lower than the optimal cooperative wage level. But if both unions tend to reduce wages to increase employment, the direct impact on employment in their own sector is (partially) offset by a decrease in demand in line with the fallacy-of-composition argument.

Note that the reaction curves are interchanged in the figures. Both cases exhibit strategic complementarity in wages. So a change in $I_{f}$ also induces multiplier effects in wages. The two cases illustrate that strategic complementarity rules out neither a negative nor a positive externality.

\section{CONCLUDING REMARKS}

In this paper we have studied a unionized economy in a two-sector general equilibrium model with imperfect competition. Unions set wages in their own sector and firms determine the level of employment. The two sectors are interrelated with each other, because agents in one sector demand goods produced in the other sector. A game is defined that consists of two subgames. In the first subgame, the unions play against each other. The outcome of this subgame is a wage vector. In the second subgame, firms are players and determine the demand for labour given the combination of wages. The model considered has interesting features apart from the issue of coordination between unions. An increase in foreign income is multiplied throughout the economy, although the model is of a general equilibrium kind. The multiplier becomes larger when the number of firms in a sector increases.

The model is solved both with non-cooperative and cooperative behaviour of unions. We compared the levels of wages and employment in the situation where unions do not take into account the external effects of their wage claims with the situation where they coordinate their activities. In a classical view, unions are held responsible for excessive wages and too low employment. From the perspective of our study, two comments on this view can be made. In the first place, high wages may not be so bad for employment, because it may stimulate demand so that the negative impact on employment is (partially) offset. In the second place, if a federation of unions exists and unions are willing 
to cooperate, lower wages can be achieved even without intervention in the labour market by the federal government.

Recently, policy coordination is one of the topics in international economics. In the literature on international coordination between countries (see e.g. Kehoe (1987)) an artificial figure of a 'world planner' has to be introduced to 'enforce' coordination between countries. No such figure is needed to represent coordinating unions in countries where federations of unions exist that are able to coordinate member unions' strategies. In such countries coordination between unions can be embedded in an existing institutional framework.

\section{APPENDICES}

\section{APPENDIX A}

In this appendix we show that $\partial y_{i}^{*} / \partial w_{i}, i=A, B$ cannot be positive. Taking the derivative of equation (9) or (10) we get

$$
\frac{\partial y_{i}^{*}}{\partial w_{i}}=-\frac{\gamma \xi I_{f} / w_{i}^{2}}{1-[\alpha+(\beta-\alpha) \xi]}-\frac{(\beta-\alpha) \xi n \sigma w_{-i} / w_{i}^{2}}{1-[\alpha+(\beta-\alpha) \xi]^{2}}, \quad i=A, B .
$$

This expression is positive only if

$$
\left[1+\alpha+(\beta-\alpha) \gamma \xi I_{f}+(\beta-\alpha) \xi n \sigma w_{-i}<0, \quad i=A, B\right.
$$

or,

$$
\alpha-\beta>(1+\alpha) \frac{\gamma I_{f}}{n \sigma w_{-i}+\gamma \xi I_{f}}>(1+\alpha) \frac{\gamma I_{f}}{n \sigma w_{-i}+\gamma I_{f}}, \quad i=A, B
$$

It is easy to see that if a set of values of $\alpha$ and $\beta$ exists that satisfies (A.1), then $\alpha$ 's near-one and $\beta$ 's near-zero are in that set. In case $\alpha=1$ and $\beta=0$ (A.1) reduces to

$$
n \sigma w_{-i}>\gamma I_{f}, \quad i=A, B
$$

Looking at equations (9) and (10), it is revealed that for $\alpha=1$ and $\beta=0$

$$
w_{i} y_{i}=-n \sigma w_{i}+\gamma I_{f}-\frac{n \sigma\left(w_{-i}-w_{i}\right)}{2-\xi}, \quad i=A, B .
$$

Using (A.2) gives

$$
w_{i} y_{i}<\frac{1}{2-\xi}\left(\gamma I_{f}-n \sigma w_{-i}\right)<0,
$$

which cannot be the case. Hence $\partial y_{i}^{*} / \partial w_{i}>0, i=A, B$, can be ruled out. 


\section{APPENDIX B}

In this appendix we arrive at equations (11) and (12). Unions choose wages such that $w_{i}^{\theta}\left(L_{i}^{*}\right)^{1-\theta}$ is maximized. The first order condition is as follows:

$$
\theta \frac{L_{i}^{*}}{w_{i}}+(1-\theta) \frac{\partial L_{i}^{*}}{\partial w_{i}}=0 \quad i=A, B
$$

Using equations (8) and (9) we know that

$$
L_{i}^{*}=y_{i}^{*}+\sigma=\frac{(1-\alpha) n \sigma+\gamma \xi I_{f} / w_{i}}{1-[\alpha+(\beta-\alpha) \xi]}+\frac{(\beta-\alpha) \xi n \sigma\left[w_{-i} / w_{i}-1\right]}{1-[\alpha+(\beta-\alpha) \xi]^{2}}
$$

and

$$
\frac{\partial L_{i}^{*}}{\partial w_{i}}=-\frac{\gamma \xi I_{f} / w_{i}^{2}}{1-[\alpha+(\beta-\alpha) \xi]}-\frac{(\beta-\alpha) \xi n \sigma w_{-i} / w_{i}^{2}}{1-[\alpha+(\beta-\alpha) \xi]^{2}}
$$

Substituting (B.2) and (B.3) in (B.1) and rearranging them, we get

$$
\frac{\gamma \xi I_{f} / w_{i}+(1-\alpha) n \sigma \theta(2 \theta-1)^{-1}}{1-[\alpha+(\beta-\alpha) \xi]}+\frac{(\beta-\alpha) \xi n \sigma\left[w_{-i} / w_{i}-\theta(2 \theta-1)^{-1}\right]}{1-[\alpha+(\beta-\alpha) \xi]^{2}}=0
$$

Multiplying the numerator and the denominator of the first term by $(1+\alpha+$ $(\beta-\alpha) \xi)$ and the whole expression by $w_{i}$, dropping the denominator $1-[\alpha+(\beta-\alpha) \xi]^{2} \neq 0$, we get

$$
\begin{aligned}
& {[1+\alpha+(\beta-\alpha) \xi] \gamma \xi I_{f}+(\beta-\alpha) n \xi \sigma w_{-i}=} \\
& \frac{\theta}{1-2 \theta}\{[1+\alpha+(\beta-\alpha) \xi](1-\alpha) n \sigma-(\beta-\alpha) \xi n \sigma\} w_{i}= \\
& \frac{\theta}{1-2 \theta}\{1-\alpha[\alpha+(\beta-\alpha) \xi]\} n \sigma w_{i} .
\end{aligned}
$$

This implies

$$
\begin{aligned}
w_{i}=\frac{1-2 \theta}{\theta}[ & \left\{\frac{1+\alpha+(\beta-\alpha) \xi}{1-\alpha[\alpha+(\beta-\alpha) \xi]}\right\} \frac{\gamma \xi I_{f}}{n \sigma} \\
& \left.+\left\{\frac{(\beta-\alpha) \xi}{1-\alpha[\alpha+(\beta-\alpha) \xi]}\right\} w_{-i}\right] \quad i=A, B .
\end{aligned}
$$


This is equation (11). Equation (11) has the following form

$$
w_{A}=\mu+\lambda w_{B} \text { and } w_{B}=\mu+\lambda w_{A},
$$

where

$$
\mu=\frac{1-2 \theta}{\theta}\left[\frac{1+\alpha+(\beta-\alpha) \xi}{1-\alpha[\alpha+(\beta-\alpha) \xi]}\right] \frac{\gamma \xi I_{f}}{n \sigma}
$$

and

$$
\lambda=\frac{1-2 \theta}{\theta}\left[\frac{(\beta-\alpha) \xi}{1-\alpha[\alpha+(\beta-\alpha) \xi]}\right] .
$$

A solution to this set of equations is

$$
w_{A}^{*}=w_{B}^{*}=\mu /(1-\lambda) .
$$

Rewriting (B.7) gives

$$
\begin{aligned}
1-\lambda= & \frac{1-2 \theta}{\theta}\left[\frac{(\beta-\alpha) \xi}{1-\alpha[\alpha+(\beta-\alpha) \xi]}\right]= \\
& \frac{\theta\left[\left(1-\alpha^{2}\right)-\alpha(\beta-\alpha) \xi\right]-(1-2 \theta)(\beta-\alpha) \xi}{\theta[1-\alpha[\alpha+(\beta-\alpha) \xi]]}
\end{aligned}
$$

Substituting (B.6) and (B.9) in (B.8) yields equation (12).

\section{REFERENCES}

Abraham, F. (1987), 'Bargaining Structures and Macroeconomic Performance in a Small Open European Economy with Imperfectly Competitive World Markets,' University of Michigan, Discussion Paper no. 200.

Calmfors, L. and J. Driffill (1988), 'Bargaining Structure, Corporatism and Macroeconomic Performance,' Economic Policy, 6, pp. 14-61.

Cooper, R. (1988), 'Will Share Contracts Increase Economic Welfare?', American Economic Review, 78, pp. 139-154.

Cooper, R. and A. John (1988), 'Coordinating Coordination Failures in Keynesian Models,' Quarterly Journal of Economics, 103, pp. 441-463.

Gylfason, T. and A. Lindbeck (1984a), 'Competing Wage Claims, Cost Inflation, and Capacity Utilization,' European Economic Review, 24, pp. 1-21.

Gylfason, T. and A. Lindbeck (1984b), 'Union Rivalry and Wages: An Oligopolistic Approach,' Economica, 51, pp. 129-139.

Hart, O. (1982), 'A Model of Imperfect Competition with Keynesian Features,' Quarterly Journal of Economics, 97, pp. 109-138. 
Kehoe, P.J. (1987), 'Coordination of Fiscal Policy in a World Economy,' Journal of Monetary Economics, 19, pp. 349-376.

Keynes, J.M. (1936), The General Theory of Employment, Interest and Money, London.

Mulder, C.B. (1988), 'Wage Moderating Effects of Corporatism. Decentralized versus centralized Wage Setting in a Union, Firm, Government Context,' University of Tilburg, Discussion Paper, FEW no. 316.

Mulder, C.B. (1989), 'Efficient and Inefficient Institutional Arrangements between Governments and Trade Unions; an Explanation of High Unemployment, Corporatism and Union Bashing,' Tilburg University, Discussion Paper, FEW no. 375.

Nickell, S.J. and M. Andrews (1983), 'Unions, Real Wages and Employment in Britain 1951-1979,' Oxford Economic Papers, Supplement, pp. 507-530.

Oswald, A.J. (1979), 'Wage Determination in an Open Economy with Many Trade Unions,' $O X$ ford Economic Papers, pp. 369-385.

Oswald, A.J. (1982), 'The Economic Theory of Trade Unions: An Introductory Survey,' Scandinavian Journal of Economics, 87, pp. 160-193.

Varian, H. (1984), Microeconomic Analysis, New York.

\section{Summary}

\section{COORDINATING UNIONS, WAGES AND EMPLOYMENT}

In this paper we consider a two-sector economy in which individual unions are affiliated into a federation of unions. We analyze the consequences of two different types of wage setting. Firstly, individual unions set wages in their own sector without taking into account the effect of their wages on the employment level in the other sector. There may be positive as well as negative externalities. A positive (negative) externality may exist if a higher (lower) wage in one sector implies a higher level of employment in the other sector. Both cases may occur in our model. Secondly, wages in the two sectors are set by the federation of unions. We show that in this case higher (lower) wages result than in the first case if a positive (negative) externality exists. 